\title{
Teacher Power and Gender in the Classroom Discourse of EFL Teacher Educators: Insights from a case study
}

\section{Reda Elmabruk $^{1} \quad$ Nesrin Etarhuni}

Faculty of Education, University of Tripoli

Received: 07-07-2021 Accepted: 07-08-2021 Available Online: 09-08- 2021

https://doi.org/10.36602/faj.2021.n18.04

\section{Abstract}

How Teacher Power (TP) is exerted impacts affective learning and class participation. This mixed-method case-study research explores TP and the role of gender in a Libyan EFL Teacher Education context. Classroom discourse is analysed to determine the scale of Teacher Power Strategies (TPS) manipulated by both male and female educators with respect to Pro-social Teacher Power (PTP) and Antisocial Teacher Power (ATP). Six teacher educators (three males and three females) have been observed over 18 lectures involving 47 second-semester students. How the student teachers perceive and react to TP is explored through focus group interviews. The findings reveal interesting gender differences in the application of anti and pro-social power; the males' TP ratio (2.3:1) is much greater than the females' (1.5:1) who display far less ATP, e.g. command power, with zero criticism and zero coercion; PTP is distinguished by politeness and compliment; "command softening", mitigated power and lowered anxiety. The students tolerate teachers' command, interruption, questioning for pedagogic reasons; cases of unwarranted coercion and unconstructive criticism are met with silent protest. In conclusion, a balance of power is deemed essential in fostering students' well-being, promoting a relaxed stress-free atmosphere, and facilitating active student participation.

Keywords: Classroom discourse; gender difference; Libyan EFL teacher education; student teachers; teacher power strategies.

${ }^{1}$ r.elmabruk@uot.edu.ly 


\section{سلطة المدرس وفروقات الجنس في الحوار الفصلي للمعلم التربوي مع طلبة اللغة الإنجليزية كلغة أجنبية: رؤى من خلال دراسة حالة التحون}

نسرين صلاح الدين الترهوبي

كلية التربية ، جامعة طرابلس
رضا خالد المبروك

ملخص البحث

يدرس هذا البحث حالة بعينها من حيث اختلافات الجنسين في استخدام سلطة المعلم مع

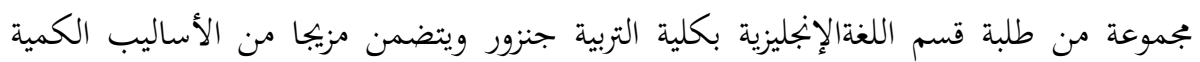
والنوعية. استخدم الباحثان أسلوب المشاهدة الفصلية لستة معلمين تربويين (ثلاثة ذكور وثلاث إناث) خلال 18 محاضرة شارك فيها 47 طالبًا وقاما بتحليل خطاب الفصل النيات الدراسي كميًا لتحديد مدى استخدام المعلم التربوي لاستراتيجيات السلطة بالإشارة إلى نوعين منها: المؤيدة

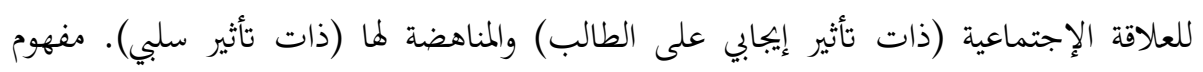

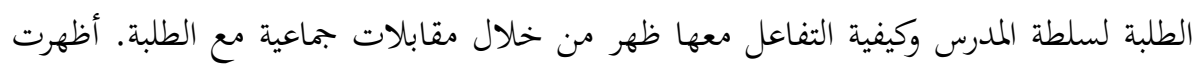
النتائج اختلافات في استخدام استراتيجيات سلطة المعلم بين الجنسين إذ كانت السلطة في مئي الخطاب الفصلي للذكور أكثر مناهضة للعلاقة الاجتماعية (2.3: 1: 1)، بينما السلطة عند الإناث

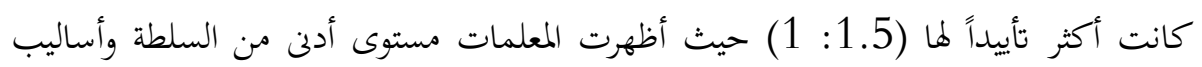

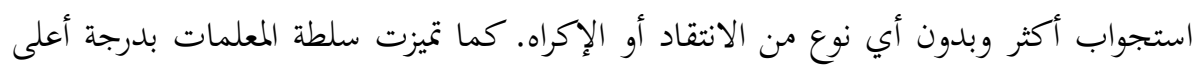

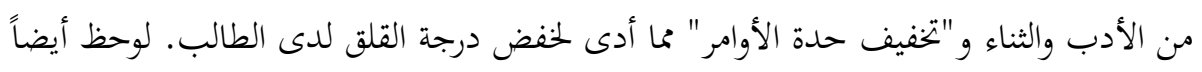

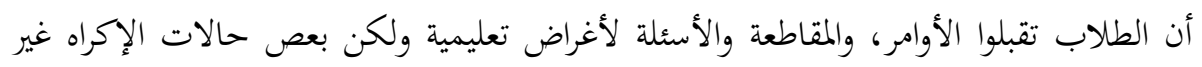

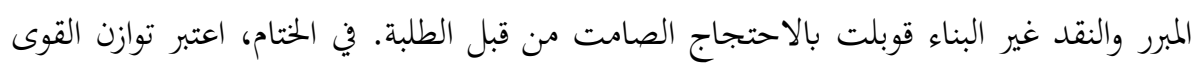

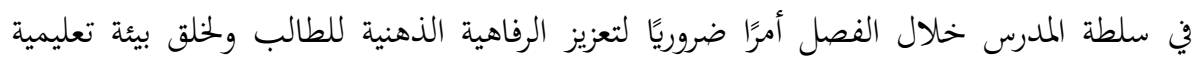
مريحة وخالية من التوتر مما يسهل مشاركة فصلية فعالة.

الكلمات المفتاحية: إعداد المعلمين لثعليم اللغة الإنجليزية كلغة أجنبية؛ استراتيجيات سلطة المعلم؛ الخطاب الفصلي؛ الطالب المعلم؛ الفروق بين الجنسين. 


\section{Introduction}

Because knowledgeable people possess power, teachers are rendered more superior over their students (Foucault, 1972). In this sense, Teacher Power (TP) is viewed as an individual's capacity to influence the behaviour of another person or group of persons (McClelland, 1975). Within the Libyan culture, teachers at all levels of education are highly respected by both students and society, and hence TP is traditionally accepted and to some extent tolerated. As McCroskey and Richmond (1983, p.176) maintain, power vests teachers with the capacity to "affect in some way the students' wellbeing beyond the students' control”, the consequences of which could be more far-reaching than initially imagined.

\subsection{Significance of the study}

The significance of the study lies in inviting teachers and lecturers to consider their perception of power and avoid, or at least minimise, its negative consequences. When teachers are conscious of the adverse consequences of power, they will be in a better position to manipulate power to reduce anxiety and promote a relaxed classroom environment. Mitigating anti-social power using "command softening" expressions has proven successful in the present study. Bearing in mind the high power distance between teachers and students within the Libyan society, an attenuation of power would almost certainly contribute to friendlier learner-centred conditions and the fostering of more active student participation.

\subsection{Research statement}

Notwithstanding the embedded social tolerance for TP, excess anti-social power, e.g., coercion or criticism, can cause harm the lesspowerful students hence causing increased anxiety and avoidance of class contribution (Chioukh, 2011). Therefore, teachers and teacher educators must develop a conscientious understanding of how to manipulate teacher power strategies, and understand how their students' affective learning is influenced by such strategies. As Reid 
and Kawash (2017) emphasise, "understanding power use in the classroom is essential to setting up positive, pro-social learning environments and avoiding the abuse (or perception of) teacher power" (p.7).

\subsection{Research questions}

Based on the underlying perspectives set out above, three pivotal research questions guided the direction of the study:

1. To what degree are anti-social and pro-social power manifested in the classroom discourse of Libyan EFL teacher educators?

2. What gender differences are exhibited in the use of anti-social and pro-social power in the teachers classroom discourse?

3. What are the students' perception of and reaction to anti-social and pro-social power?

\section{Conceptual framework}

\subsection{Teacher power and discourse}

As teachers apply power through discourse, its impact is felt by students in more than one way; in their affective learning (McCroskey \& Richmond, 1983), motivation to participate in class activities (Richmond, 1990); in their academic achievement (Diaz, Cochran \& Karlin, 2016). As a result, teachers are vested with the capacity to modify behaviour through the power of classroom discourse.

Hurt, Scott and McCroskey (1978) emphasise an interrelationship of power with discourse by advocating a "difference between knowing and teaching, and that difference is communication in the classroom" (p. 3). Maftoon and Shakouri (2012, p.1208) stress that power is "linguistically expressed by teachers and presented in the classroom". According to Kearney, Plax, Richmond, and McCroskey (1985), teacher power discourse is expressed not only by content-knowledge alone but more specifically through the manipulation of discursive strategies; "we now realize that knowledge of content material is an 
insufficient condition to instruction; the practising teacher must learn the communication strategies that can control student behaviours requisite for learning" (p. 5).

\subsection{Teacher power strategies}

Kearney et al. (1985, p.6) associate TP with "power strategies" that comprise "behaviour alteration techniques which teachers use to control or modify student actions; if power strategies are not employed, the teacher's ability to enhance student learning is reduced thus, power strategies are critical to teaching effectiveness and classroom management" (Kearney et al., 1985, p.5).

A categorization of Teacher Power Strategies (TPS) typically implemented in classroom discourse has been extracted from the literature. This classification identifies eight sources of power used in this study to assess manifested power:

1. Command: As one of the most common forms of TP (Monsefi \& Hadidi, 2015), this type typically involves the use of imperatives to issue instruction.

2. Questioning: Questioning is an essential classroom activity which teachers use to elicit information, check comprehension, or evaluate students. Fairclough (1989, p. 46) asserts that a teacher "has the right to give orders and ask questions, whereas the students have only the obligation to comply and answer".

3. Interruption: According to Zimmerman and West (1975, p. 103) interruption is a "device for exercising power and control in conversation" as people with high-power status can interrupt other speakers and thus control discourse.

4. Criticism: Teachers legitimately possess the power to be critical of students. As Lahlali (2003, p. 156) points out, criticism may have negative effects; it can "discourage and intimidate the learner and may even stop him answering future questions". 
5. Coercion: Coercive power is known to have negative consequences on learning (McCroskey \& Richmond, 1983). It is based on learners' expectations that they would be penalised if they do not adhere to requirements; thus "the strength of a teacher's coercive power is contingent upon the student's perception of how probable it is that the teacher will exact punishment for non-conformance" (McCroskey \& Richmond, 1983, p. 181).

6. Politeness: According to Senowarsito (2013), politeness involves using appropriate words in context; a tactic that is governed by social norms. Hence, a teacher may mitigate power with forms of politeness to make learners feel at ease.

7. Compliment: Offering compliment or praise is another strategy that reduces power. Chioukh (2011, p. 148) points out that one common way of giving a compliment is positive feedback, which can 'boost learners' sense of confidence and simultaneously decreases their language anxiety which is very common in FL classroom".

8. Reward: This form of power "involves introducing something pleasant or removing something unpleasant, if the student does comply" (McCroskey \& Richmond, 1983, p. 177). Shindler (n.d.) states that teachers may use reward power, e.g. grades, prizes, or privileges, in different ways to influence learners' behaviour. $\mathrm{He}$ warns, however, that the influence of reward is associated with how desirable that reward is to students.

\subsection{Anti-social and pro-social power}

Schrodt, Whitt and Turman (2007) attribute the positive impact of TP to pro-social strategies, such as complement and reward, which have motivating effects on students (Diaz, Cochran \& Karlin, 2016). Reid and Kawash (2017) confirm that pro-social power positively impacts motivation and learning. Negative power is associated with the exertion of anti-social strategies, e.g. interruption, coercion and 
criticism. Chioukh, (2011) points out that command, criticism, coercing, interruption, and questioning in various degrees do cause increased student anxiety. Table 1 classifies TPS into Anti-social Teacher Power (ATP; 1-5) and Pro-social Teacher Power (PTP; 6-8).

Table 1: Sources of anti and pro-social power

\begin{tabular}{ccclll}
\hline ATP & 1.Command & 2.Questioning & 3.Interruption & 4.Criticism & 5.Coercion \\
\hline PTP & 6.Politeness & 7.Compliment & 8.Reward & &
\end{tabular}

\subsection{Teacher Power and gender}

Regarding the association of teacher power with gender, researchers have held dissimilar views. Some assert that there is a relationship between teacher power and gender; others believe that there is no relationship.

Previous studies by Monsefi and Hadidi (2015); Rashidi and Naderi (2012); Fikri, Dewi and Suarnajaya (2014) found that gender is an important variable in the distinction between male and female classroom discourse. On the other hand, studies by Rashidi and Rafieerad (2010); Li and Guo (2012) reveal that no relationship between teacher power and gender were found.

Doray $(2005$, p. 180) confirms that variation in TP is not due to gender; "context determines discourse rather than gender". $\mathrm{He}$ explains that "in the teaching situation, the occupational variable which invests the teacher with authority and power allows both female and male teachers to adopt different features of masculine and feminine discourse" (p. 119).

\section{Methodology}

This paper adopted a case-study design with a mixed-method approach. A case study is characterized by in-depth inquiry where data describes and explains the explored phenomenon (Ishak \& Abu Bakar, 2014). The typicality of case (commensurate with a sampling frame in quantitative research) is also significant in case-study 
research, which Bassey (1993, p. 62) describes in the sense of singularity that is "expected in some way to be typical of something more general; the focus is the issue not the case as such".

Mixed-methods research implies the integration of quantitative and qualitative methods as components of a research design (Creswell, 2009). The mixed-method approach in this study combines qualitative research methods (observations and focus groups) with quantitative measurement techniques (percentages and ratios) to generate complementary qualitative and quantitative data (Caruth, 2013), which enhances the robustness and rigor of findings.

\subsection{Participants}

A convenient ample of six teachers (three males and three females), all with MA English certification, voluntarily participated in the case study. Table 2 summarizes their background information including age, experience, subjects taught, and the hours observed. To maintain anonymity, the participating teachers are referred to alphabetically from A to F.

Table 2: Background information

\begin{tabular}{cllccc}
\hline Teacher & Gender & Age & $\begin{array}{c}\text { Teaching } \\
\text { experience }\end{array}$ & $\begin{array}{c}\text { Subject } \\
\text { taught }\end{array}$ & $\begin{array}{c}\text { Hours } \\
\text { observed }\end{array}$ \\
\hline A & Male & 57 & 33 & Reading & 3 \\
\hline B & Male & 47 & 10 & Writing & 4 \\
\hline C & Male & 57 & 35 & Grammar & 4 \\
\hline D & Female & 34 & 5 & Listening & 3 \\
\hline E & Female & 31 & 7 & Vocabulary & 4 \\
\hline F & Female & 43 & 19 & Speaking & 4 \\
\hline & & & & & 22 \\
\hline
\end{tabular}

The student population consisted of 62 second-semester students of English at the Faculty of Education Janzour. 47 of these sophomores (46 females and 1 male, aged between 17 and 23), who were enrolled for the listed subjects, constituted a convenient sample and volunteered to participate in the focus group interviews. The 
female students clearly outnumbered the males due to the fact that faculties of education in Libya are largely less favoured by male students (though not necessarily at such a low proportion).

\subsection{Instruments}

- Classroom observation: Having obtained the case teachers' consent to being observed, it was deemed necessary to initially conceal the exact purpose of the study to minimise threats to internal validity. Observed teacher behaviour should occur authentically, not due to reactivity (e.g. Praetorius, McIntyre \& Klassen, 2017). When later debriefed, all case teachers confirmed they would have probably manipulated their power strategies in some way had they been aware of the exact purpose of research. The teachers were observed over 18 lectures with 22 hours of observation. The sessions averaged one hour twenty minutes.

- Focus Group Discussion (FGD): Seven focus groups were organized to fit in with the students' schedule. Two main themes of discussion were raised; students' perceptions of teacher power and how it impacts their classroom behaviour and involvement in class activities.

\section{Data analysis}

Observed TPS were categorized as either anti or pro-social power according to the classification in Table 1. Tokens of power for each teacher were expressed in terms of percentages and ratios with respect to individual total power discourse. These strategies were then totalled and contrasted with one another for gender differences. Content analysis highlighted relevant extracts from the students' FGDs; insertions in square brackets were added to clarify intended meaning where applicable. 


\section{Discussion and findings}

\subsection{Manifestation of power}

Table 3 illustrates the teachers' ATP contrasted with PTP in descending order (top to bottom) and the ensuing TP Ratio (the ratio of ATP to PTP).

Table 3: Manifested TP

\begin{tabular}{|c|c|c|c|c|c|}
\hline & $T P S$ & Freq. & $\%$ & Cum \% & TP Ratio \\
\hline \multirow{6}{*}{ ATP } & Command & 615 & 36.7 & 36.7 & \multirow{6}{*}{2.3} \\
\hline & Questioning & 442 & 26.4 & 63.1 & \\
\hline & Interruption & 75 & 4.5 & 67.6 & \\
\hline & Criticism & 22 & 1.3 & 68.9 & \\
\hline & Coercion & 7 & 0.4 & 69.3 & \\
\hline & Subtotal & 1161 & 69.3 & - & \\
\hline \multirow{4}{*}{ PTP } & Politeness & 343 & 20.5 & 20.5 & \multirow{4}{*}{1} \\
\hline & Compliment & 167 & 10 & 30.5 & \\
\hline & Reward & 5 & 0.2 & 30.7 & \\
\hline & Subtotal & 515 & 30.7 & - & \\
\hline
\end{tabular}

\subsubsection{Anti-social strategies}

Overall, the educators exhibited a higher degree of anti-social power $(69.3 \%)$ when compared with pro-social $(30.7 \%)$ at more than twice the ratio (2.3:1). ATP was predominantly displayed through Command (36.7\%), a finding that is consistent with Monsefi and Hadidi (2015); Hidayati, Zen and Basthomi (2017).

Questioning (26.4\%) was the second most frequent ATP with open-ended questions being posed more often than yes/no questions. Students mostly responded in short phrases or sentence fragments. This excerpt is from Teacher C's class:

(1) T: How can you form the negative form of imperative?

S1: Not!

$\mathrm{T}$ : Yes, but what comes before not?

S2: Do not! 
T: Thank you! Do not or don't. Give me an example.

S2: Don't come late.

$\mathrm{T}$ : Very good, thank you.

Teachers' Interruption, Criticism and Coercion constituted $6.2 \%$ of total ATP. Interruption was used primarily to correct students' grammar and pronunciation. Being a grammar instructor, Teacher $\mathrm{C}$, displayed the highest Interruption power (13.5\%).

Criticism appeared low (0.4\%). It was used in association with slow progress, or failure to engage in discussion:

(2) I think I've done [a] big effort but without any benefit (Teacher A).

(3) You are university students... you aren't high school students (Teacher B).

(4) You are not with us; you're sleeping (Teacher C).

As Teacher A praised himself for "doing big effort" (2), he criticised class progress (without any benefit). Despite such unconstructive criticism, the students did not object or argue; they sombrely endure it in silence. Teacher B (3) criticised them again for low competence comparing them with high school students. Though the students were dissatisfied, they could not contradict the teacher, for he possessed the authority to criticise, be it unconstructively.

In (4), Teacher C caught a student 'daydreaming'. He asked her a question, and she looked in bewilderment. Her classmate tried to help by whispering something, but it was too late; the teacher had delivered his verdict: "you're sleeping".

The reported incidents of Criticism (4-6), appear unconstructive, i.e. they lacked a well-reasoned opinion, gave negative personal comments in a non-friendly manner. Tolerance for teacher power is by convention embedded in the Libyan culture; students traditionally show respect to the teacher by remaining silent and only speak when asked (Wagner, 1993). 
Altmiller (2016) points out that unconstructive criticism is linked to irresponsible teacher behaviour and can cause harm to the relationship with students, thus fuelling possible retaliation in response. Moreover, unconstructive criticism is likely to reduce motivation and limit engagement with upcoming feedback (Ibrahim, MacPhail, Chadwick and Jeffcott, 2014).

Teacher A appeared to be the only educator to use Coercion:

(5) You are playing with your phone... looking at your photos.

You'll be doing [repeating] Reading Two next semester.

(6) I'll fail you all. Next semester you'll be doing Reading Two.

In (5), a strong unwarranted, form of coercion (repeating Reading 2) was applied to reprimand a student who was looking at photos in her mobile during the lecture. Feeling rather embarrassed, she put her phone away and looked down silently. In (6), as the class did not answer a question, the teacher resorted to unwarranted coercion; this time to "fail all". However, the students did not object outwardly; perhaps as Benesch (1999) notices, silence may be interpreted as a protest. Silent resistance meant also that the students withdrew from further classroom interaction.

\subsubsection{Pro-social strategies}

The pro-social strategies displayed $(30.7 \%)$ indicate a moderate level of positive power. Politeness $(20.5 \%)$ was affected through expressions such as please.../can/could/would you? which reduced the impact of command power. The highest rate of Politeness $(30.1 \%)$ was demonstrated by female Teacher D.

Complement (10\%) was used to praise and motivate students, e.g. good; that's good; thank you; well done; excellent. Such forms of praise encouraged the students to take part without worrying too much about mistakes since incorrect answers were acknowledged. Teacher D frequently complimented contributions regardless of quality: 
I want you to answer questions with no worry; don't worry if you answer wrong way [wrongly], just try to express yourself.

Such error tolerance encouraged student contribution; it reduced anxiety and facilitated stress-free learning (Altun, 2015; Bran, 2018). Other teachers, e.g. Teacher A, rarely offered compliment (1.8\%). A lack of praise associated with unconstructive criticism raise anxiety and harm affective learning (Chioukh, 2011).

Though Reward (0.2\%) was seldom used by the educators, it was offered bizarrely, e.g. by Teacher A:

(7) If you tell me [the] right topic, you [can] go to Reading Three from now.

(8) I think I [will] let you pass to Reading Three.

The students were 'promised' to pass to the next level of Reading and "from now" if they could guess the topic for a given paragraph, which was both impractical and unacceptable.

\subsubsection{Gender differences in TP}

Table 4 contrasts ATP and PTP by males and females. It shows individual teacher power strategies $(\mathrm{A} \%-\mathrm{F} \%)$ and the total $(\mathrm{sum} \%)$ for each one. 'Ratios' represents TP ratios for each case teacher.

Table 4: Male and female power

\begin{tabular}{|c|c|c|c|c|c|c|c|c|c|c|c|}
\hline \multirow[b]{2}{*}{$T P S$} & & \multicolumn{5}{|c|}{ Male Educators } & \multicolumn{5}{|c|}{ Female Educators } \\
\hline & & $A \%$ & $B \%$ & $C \%$ & Sum $\%$ & $\begin{array}{l}\text { TP } \\
\text { Ratio }\end{array}$ & $D \%$ & $E \%$ & $F \%$ & Sum\% & $\begin{array}{l}\text { TP } \\
\text { Ratio }\end{array}$ \\
\hline \multirow{6}{*}{$\begin{array}{l}\text { AT } \\
\mathbf{P}\end{array}$} & Command & 68.2 & 41.8 & 37.6 & 49.3 & \multirow{6}{*}{3.5} & 20.7 & 16.4 & 32.6 & 19.8 & \multirow{6}{*}{1.4} \\
\hline & Questioning & 22.1 & 25.5 & 12.2 & 19.1 & & 32.2 & 22.1 & 32.6 & 34 & \\
\hline & Interruption & 0 & 0 & 13.5 & 4.5 & & 0.6 & 0.8 & 12.8 & 4.3 & \\
\hline & Criticism & 1.8 & 5.1 & 0.7 & 2.3 & & 0 & 0 & 0 & 0 & \\
\hline & Coercion & 2.1 & 0 & 0 & 1.0 & & 0 & 0 & 0 & 0 & \\
\hline & Subtotal & 94.2 & 72.4 & 64 & 77.6 & & 53.5 & 39.3 & 45.4 & 58.1 & \\
\hline \multirow{5}{*}{ PTP } & Politeness & 3.1 & 24.7 & 21.2 & 15.3 & \multirow{5}{*}{1} & 30.2 & 19.1 & 11.9 & 25.8 & \multirow{5}{*}{1} \\
\hline & $\begin{array}{l}\text { Complimen } \\
\mathrm{t}\end{array}$ & 1.8 & 2.9 & 14.8 & 6.3 & & 16.3 & 40.2 & 6 & 14 & \\
\hline & Reward & 0.9 & 0 & 0 & 0.3 & & 0 & 1.3 & 0.4 & 0.2 & \\
\hline & Subtotal & 5.8 & 27.6 & 36 & 22.4 & & 46.5 & 60.6 & 18.3 & 40.8 & \\
\hline & Ratios & $16.2: 1$ & $2.6: 1$ & $1.8: 1$ & $3.5: 1$ & & $1.1: 1$ & $0.6: 1$ & $4.2: 1$ & $1.4: 1$ & \\
\hline
\end{tabular}


Interesting gender differences in the use of TPS have emerged. The females used anti-social strategies less frequent (59.2\%) than the males $(77.6 \%)$. This finding confirms results of previous studies by Monsefi and Hadidi (2015); Rashidi and Naderi (2012); Hidayati, Zen and Basthomi (2017); Fikri, Dewi and Suarnajaya (2014).

Conversely, the females exhibited higher pro-social power (40.8\%) almost twice as much as the males (22.4\%) with more expressions of politeness and praise. This helped to reduce learner anxiety and created a relaxed classroom atmosphere for the students, hence attracting active involvement (Said and Weda, 2018).

Figure 1 highlights gender differences in using anti-social strategies. Command by the males was more frequent $(49.3 \%)$ than females $(19.8 \%)$. The female educators mitigated command power through what was termed "command softening" by introducing attenuating expressions such as try to and just..., which mitigated the impact of command, a technique that was not observed in the male teachers' discourse.

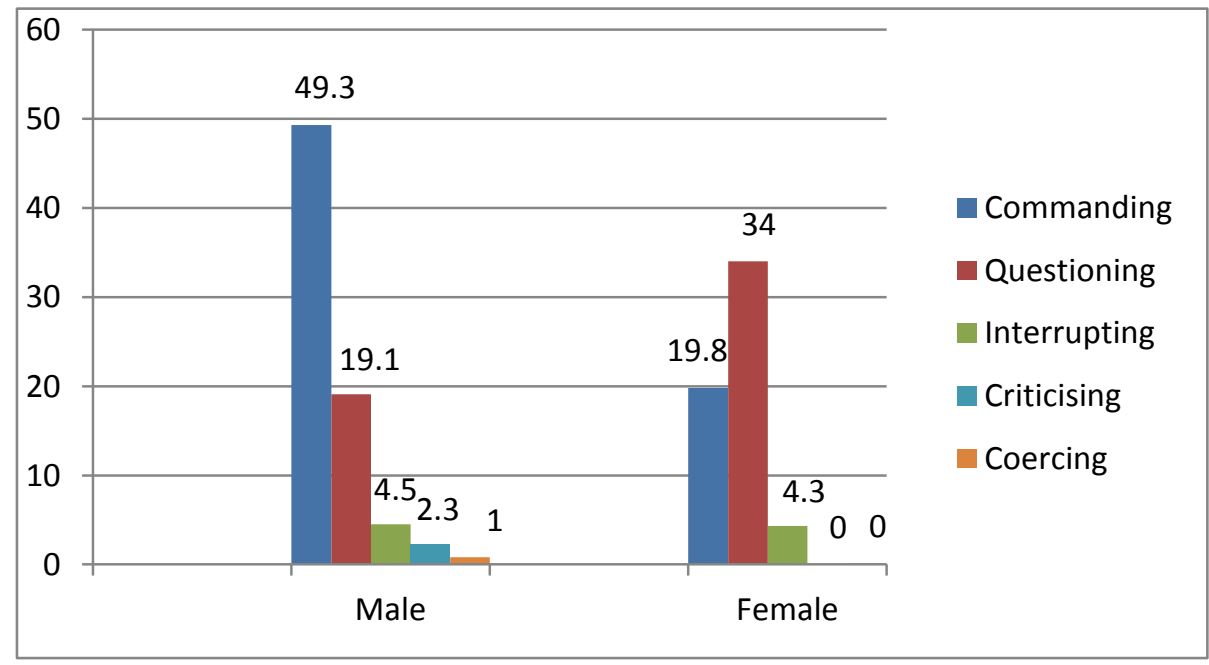

Figure 1: ATP by male and female teachers 
Interruption was used almost equally by both sexes $(4.5 \%$ by males; $4.3 \%$ by females). Whereas criticism, unconstructive at that, was exercised 22 times $(2.3 \%)$ by the male educators, it was missing from the females' discourse, i.e. zero criticism. The same was true for Coercion power (zero coercion). This "non-critical non-coercive" tactic minimized the impact of TP and created an increasingly relaxed and stress-free environment that supported active class participation.

Contrasting male and female pro-social power (Figure 2) reveals higher female pro-social strategies, e.g. Politeness $(25.8 \%)$. This is consistent with findings by Monsefi and Hadidi (2015); Fikri, Dewi and Suarnajaya (2014); Rashidi and Naderi (2012) who confirm less use of overall female power.

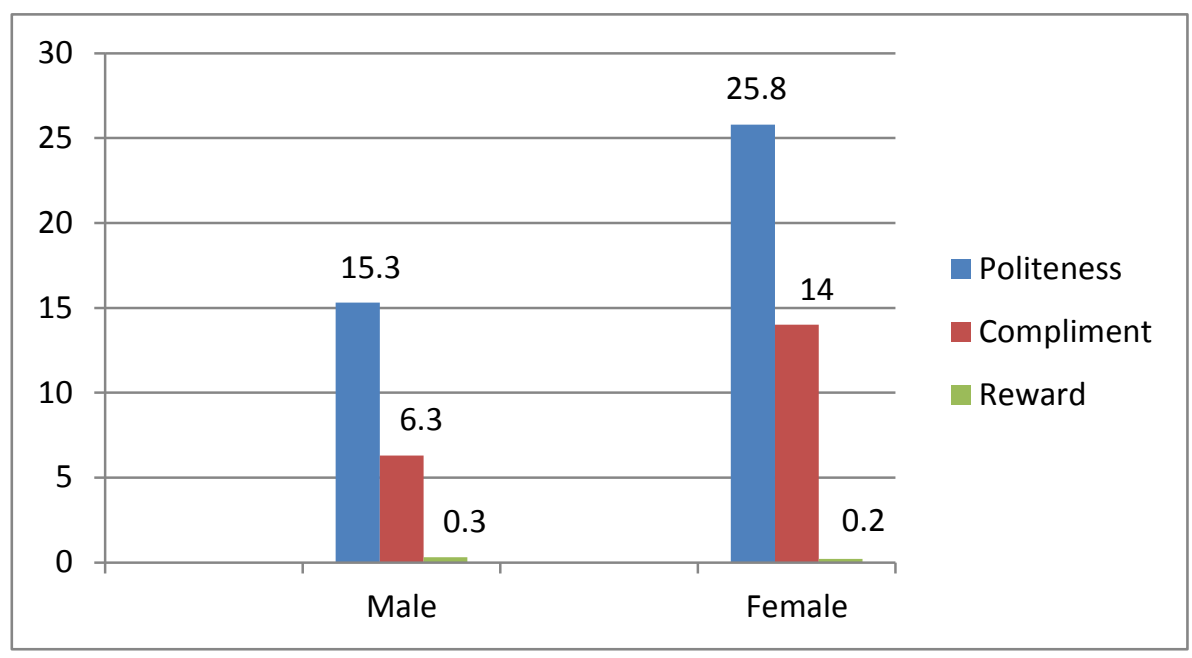

Figure 2: PTP by the male and female teachers

The female teachers also used over two times the Complement strategies (14\%) displayed by the males $(6.3 \%)$, a result which agrees with studies by Monsefi and Hadidi (2015); Rashidi and Naderi (2012); Fikri, Dewi and Suarnajaya (2014). Reward power was negligent and almost similar for both males and females $(0.3 \%$ and $0.2 \%$ consecutively). 
Based on TP Ratios in Table 4, it is apparent that the females approached a balance of power much more so than their male counterparts (1.4:1 in contrast with 3.5:1). Remarkably, for female Teacher D the scale of power was in favour of pro-social strategies with a ratio of $0.6: 1$; that is PTP was almost half that of ATP.

\subsection{Perceptions and reactions of students}

The students' perceptions of and reactions to teacher power revealed through the focus groups are discussed in terms of anti-social and pro-social power.

\subsubsection{Tolerable anti-social power}

Unanimously, the students acknowledged TP and accepted the teachers' privilege to exercise reasonable power, principally to accomplish pedagogic objectives, e.g. maintain discipline, hold attention, issue instruction, pose questions, maintain respect and, to a certain extent, interrupt students if necessary.

\subsubsection{Intolerable anti-social power}

All the students opposed excessive anti-social power. For them, it was unacceptable; it deeply concerned their emotional well-being, e.g. feeling afraid or scared, discouraged, uncomfortable, or unconfident. More importantly, it was felt that too much anti-social power impacts cognitive development, keeping up with lectures, asking questions, expressing opinions or participating in class activities.

Specific strategies of anti-social power, e.g. Command were rejected by most students (38). Instead, they preferred a modified or mitigated version of command:

S1: The student should feel being asked to do something not being ordered, and that would make [a] difference.

S2: I don't like [the] teacher when [he/she] say[s] 'do that', 'not to do that'. I think 'please', 'could you', 'do you mind' is more politely [polite]. 
Teacher interruption was a thorny issue. A majority of the students (39) disliked being interrupted for no apparent reason. It could lead to loss of focus and withdrawal from an activity.

S3: When the teacher interrupt [s] anyone [it] is not polite and I'll not be comfortable with [the] teacher who interrupt [s] me all the time. I will not focus, and I will not say anything.

Teacher interruption for cognitive gains was nevertheless tolerated by most students (32), e.g. to supplement or rectify a response, or to correct grammar/ pronunciation mistakes.

S4: Sometimes [it's] good for teachers, maybe to correct an answer and put another idea to help [the] student; to give him some words to keep him going. Sometimes [a student] [is] feeling shy, so interrupt[ion] maybe [may] help the student.

S5: I like [the] teacher when [he/she] correct [s] my grammar. I want [to] improve grammar to be [a] good teacher. Sometimes [the] teacher correct[s] pronunciation. In speaking, pronunciation must be in [a] good way.

However, being interrupted for non-cognitive purposes (e.g. when making a presentation, expressing an opinion, or when engaged in an open activity) was disliked by the majority of students (42). For them, interruption makes them confused, lose confidence, or feel unimportant:

S6: Teacher interruption confuse[s] me; I lose the point. That happens with me many times. [It] make[s] me confused.

S7: When [the] teacher interrupted [interrupts], [the] students won't feel confident.

S8: It [interruption] makes me feel [that] what I say isn't important and I don't have to participate again.

One student praised her (female) teacher who encouraged her to speak freely without paying attention to mistakes. Such attitude of error tolerance was praised by all students: 
S9: I like her way (Teacher D). She said we should speak with no worry about [the] mistakes we do. Now I feel confidence [confident] to speak in her class.

Criticism is a sensitive issue for students. Criticism often overlaps with interruption; a teacher may criticise by immediately interrupting a student, or delay the criticism till later. In either case, (immediate or delayed) criticality can be constructive or unconstructive; a topic of interest under corrective feedback. As a matter of fact, a large majority of students (45) hated immediate criticism, especially in front of peers, to the point of complete withdrawal from further activities.

S10: I don't like [it] when [the] teacher criticise[s] me in front of [the] class. I feel embarrassed; it's not good for me if [the] teacher [is] critical all the time; I stop talking.

The students thought the teacher should first listen, then criticise afterwards (delayed criticism) as necessary:

S11: The teacher has to listen carefully and then respond and interact with the students.

Criticising improper behaviour was deemed a teacher's duty by all students, so long as he/she deals with it in a non-provocative manner.

In response to Teacher A's coercive power, the students reacted to two types of coercion. One was unwarranted (threat of being failed) which they met with silent resistance on two occasions and withdrew from further contribution; a counterproductive consequence to coercive treatment. Keeping silent was the only form of resistance whilst maintaining respect for the teacher. On a third incident, a humorous variety of coercion (the threat of being thrown out of the window if they do not bring their pencils) emerged. The students took this kind of threat with a sense of humour. 


\subsection{Pro-social power}

Contrary to their views on anti-social power, the students unanimously favoured teachers who exercised pro-social power more often, e.g. politeness and complement. Instead of exerting control purely to impose authority, the students expected teachers to come down to their level, be polite and offer praise to make them feel less anxious and more motivated to participate.

S12: Teachers who minimise [power] are better; this makes you love [the] teachers more and appreciate and respect them more.

S13: Less power helps to feel relaxed in the lecture, [the result of which is] asking and understanding more.

S15: Politeness is very good to use because [it] make[s] [the] teacher have [a] relationship like father and sons. I like this teacher to learn and participate with.

S17: I prefer the medium between them [anti and pro-social power], because eventually he is a teacher, and he is on the top of students [has higher status]; I think he should be in the middle [adopt a middle position].

\section{Conclusion}

The case teachers' manifestation of power was loaded with more anti-social than pro-social power, resulting in over twice the ratio (2.3:1). Command (36.7\%) was the most common to provide instruction and maintain control; questioning rated second (26.4\%) with more open questions to engage students. Interruption power appeared much less $(4.5 \%)$ mainly to correct mistakes. Occasions of unconstructive criticism (1.3\%) and unwarranted coercion $(0.4 \%)$ were unwelcome but confronted with silent protest.

Remarkable gender differences emerged. The females manifested far less ATP in terms of command but employed more questioning that motivated student interaction. Impact of command power was mitigated by 'command softening' expressions. Little gender differences occurred regarding interruption or reward. A higher ratio of Politeness and Compliment was observed which, in combination 
with zero criticism and zero coercion and a tolerance for error, notably reduced student anxiety and facilitated livelier class participation.

The student teachers acknowledged the privilege of educators to exercise power. The students tolerated command and questioning to facilitate instruction. Interrupting was welcome to augment response or correct mistakes, but not while engaged in dialogue or free activity. The students had to endure unconstructive criticism and unwarranted coercion with silent resistance. Whereas excessive anti-social power discouraged contribution, teachers with low power risked losing students' respect.

\section{Recommendations}

Libyan EFL teachers and educators are encouraged to undergo a shift in attitudes from traditional teacher-centred to learner-centred pedagogy that is based on 'students' needs and shared power relations" (Vasiliadi, 2018, p. 18).Since TPS are critical to effective teaching (Kearney et al., 1985), teachers should employ power more consciously to facilitate learning. They should balance their act of power in such a way that it is not too anti-social to trigger anxiety, nor should it be too pro-social that control is lost.

According to Krashen's (1981) affective filter hypothesis, factors such as anxiety, motivation, and self-confidence influence learning. Therefore, teachers are advised to minimise anti-social power e.g. unnecessary interruption, unconstructive criticism, and unwarranted coercion, which hinder learner motivation and self-confidence. Command softening techniques to mitigate power may be used to reduce anxiety and create positive affective learning.

The frequent students' errors and the typically fragmentised responses expose by the verbatim extracts reveal a somewhat low level of competence incommensurate with teachers of English to be. While a tolerance for grammar errors is not recommended in teacher education contexts in particular, it has been shown to encourage stress-free engagement in speaking classes. Nevertheless, despite 
increased student engagement observed under error-tolerant teachers, the researchers argue that an open error-tolerance, particularly in EFL teacher education, can be counterproductive.

\section{Limitations and further research}

The authors acknowledge the small number of case teachers in the study (six). However, in covering 18 lectures and 22 hours of audiorecorded observations a huge amount of data was collected. Moreover, a case study as Tsang (2014) argues usually entails a small sample of participants within a reasonably controlled environment, where "the experiences, features, behaviours, and processes of a bounded unit" are understood in context (Duff \& Anderson, 2015, p.112).

Additionally, as this study investigates, for the first time, how TP is manifested through classroom discourse of Libyan EFL teacher educators, the scope and reliability of the findings could be supported by extending research to other Faculties of Education, or pedagogic contexts in Libya and/or beyond.

\section{References}

Altmiller, G. (2016). Strategies for Providing Constructive Feedback to Students. Nurse Education (41), 118-9.

Altun, M. (2015). Using Role-Play Activities to Develop Speaking Skills: A Case Study in the Language Classroom. International Journal of Social Sciences \& Educational Studies 1(4).

Bassey, M. (1993). Case Study Research in Educational Settings. McGraw-Hill Education (UK).

Benesch, S. (1999). Rights Analysis: Studying power relations in an academic setting. English for Specific Purposes, 8(4), 313-327.

Bran, R. (2018). The Role of Active Listening In the Acquisition of Second Languages. Research and Science Today, 1(15), 88-94.

Caruth, G. D. (2013). Demystifying Mixed Methods Research Design: A Review of the Literature. Melvana International Journal of Education, 3(2), 112-122. 
Chioukh, C. (2011). Interaction in Teachers/Learners and Learners/Learners' Discourse: The Case of Third Year Oral Expression Student-teachers/Teachers, Mohamed Saddik Ben Yahia (Published Master thesis). University of Ferhat Abbas-Setif, Algeria.

Creswell, J. (2009). Editorial: Mapping the Field of Mixed Methods Research. Journal of Mixed Methods Research, 3(2), 95-108.

Diaz, A. Cochran, K. and Karlin, N. (2016) The Influence of Teacher Power on English Language Learners' Self-Perceptions of Learner Empowerment, College Teaching, 64(4), 158-167.

Doray, M. B. (2005). Gender differentiated discourse: a study of teacher discourse in the adult ESL classroom. Master's dissertation, Curtin University of Technology.

Duff, P. A. and Anderson, T (2015). Case Study Research Ch. 14). In Cambridge Guide to Research in Language, C, Coombe and J. D. Brown (Eds.). Cambridge, CUP.

Fairclough, N. (1989). Language and Power. Harlow, England: Longman.

Fikri, Z., Dewi, N., Suarnajaya, W. (2014). Mood Structure Analysis of Teacher Talk in EFL Classroom: A Discourse Study Based on Systemic Functional Linguistic Theory. E-Journal Program Pascasarjana Universitas, 2.

Foucault, M. (1972). The Archeology of Knowledge and the Discourse on Language. New York: Penguin Books.

Hidayati, M., Zen, E. L. and Basthomi, Y. (2017). Indonesian Teachers' Directives in English Language Classrooms. The $4^{\text {th }}$ International Conference on Language, Society and Culture in Asian Contexts, KnE Social Sciences, 164-174.

Hurt, H. T., Scott, M. D., and McCroskey, J. C. (1978).

Communication in the Classroom. Reading, MA: AddisonWesler.

Ibrahim, J. MacPhail, A., Chadwick, L. and Jeffcott, S. (2014). Interns' Perceptions of Performance Feedback. Medical Education (48) 417-29. 
Ishak, N. M. and Abu Bakar, A. Y. (2014). Developing Sampling Frame for Case Study: Challenges and Conditions, World Journal of Education, 4, 3.

Kearney, P, Plax, T. G., Richmond, V. P. and McCroskey, J. C. (1985). Power in the Classroom III: Teacher Communication Techniques and Messages, Communication Education, 34(1), 1928.

Krashen, S. (1981). Second Language Acquisition and Second Language Learning. Oxford: Pergamon Press.

Lahlali, E. M. (2003). Moroccan Classroom Discourse and Critical Discourse Analysis: The Impact of Social and Cultural Practice, Published Doctoral dissertation. University of Leeds, UK.

Li, D., and Guo, X. (2012). A Comparison of Power Distance of Chinese English Teachers and Chinese Non-English Teachers in Classroom Communication. Intercultural Communication Studies, 21(1), 221-239.

Maftoon, P. and Shakouri, N. (2012). The Concept of Power in Teacher Talk: A Critical Discourse Analysis. World Applied Sciences Journal, 19(8), 1208-1215.

McClelland, D. C. (1975). Power: The Inner Experience. New York: Irving Publishers Inc.

McCroskey, J. C. and Richmond, V. P. (1983). Power in the classroom I: Teacher and student perceptions. Communication Education, 32, 175-184.

Monsefi, M. and Hadidi, Y. (2015). Male and Female EFL Teachers' Politeness Strategies in Oral Discourse and their Effects on the Learning Process and Teacher-Student-teacher Interaction. International Journal on Studies in English Language and Literature (IJSELL), 3(2), 1-13.

Praetorius, A-K., McIntyre, N.A. and Klassen, R.M. (2017). Reactivity Effects in Video-based Classroom Research: An investigation using teacher and student questionnaires as well as teacher eyetracking. Zeitschrift für Erziehungswissenschaft. ISSN 1434$663 \mathrm{X}$. 
Rashidi, N., and Naderi, S. (2012). The Effect of Gender on the Patterns of Classroom Interaction. Education, 2(3), 30-36.

Rashidi, N. and Rafieerad, M. (2010). Analyzing Patterns of Classroom Interaction in EFL Classrooms in Iran. The Journal of Asia TEFL, 7(3), 93-120.

Reid, L. F., and Kawash, J. (2017). Let's Talk about Power: How teacher use of power shapes relationships and learning. Papers on Postsecondary Learning and Teaching: Proceedings of the University of Calgary Conference on Learning and Teaching, 2, 34-41.

Richmond, V. P. (1990). Communication in the Classroom: Power and motivation, Communication Education, 39.

Said, M. M. and Weda, S. (2018). English Language Anxiety and its Impacts on Students' Oral Communication among Indonesian Students: A Case Study at Tadulako University and Universitas Negeri Makassar. TESOL International Journal, 13(3), 21-30.

Schrodt, P., Whitt, P.L., and Truman, P.D. (2007). Reconsidering the Measurement of Teacher Power Use in the College Classroom. Communication Education, 56(3), 308-332.

Senowarsito, N. (2013). Politeness Strategies in Teacher-Studentteacher Interaction in an EFL Classroom Context. TEFLIN Journal, 24(1), 82-96.

Shindler, J. (n.d.) The Five Forms of Teacher Power. California State University, USA.

Tsang, E. W. K. (2014). Generalizing from Research Findings: The merits of case studies. International Journal of Management Reviews, 16, 369-383.

Vasiliadi, V. (2018). Exploring classroom power relations: A qualitative approach of teacher-student interaction within the multilingual language classroom of a rural region in Crete. Postgraduate dissertation, School of Humanities, Hellenic Open University, Greece.

Wagner, A. (1993). Literacy, Culture and Development. Cambridge: Cambridge University Press. 
Zimmerman, D. H. and West, C. (1975). Sex Roles, Interruptions and Silences in Conversation. In Thorne, B. and Henley, N. (eds.) Language and Sex: Differences and Dominance, pp. 105-129. Rowley, MA: Newbury House. 